\title{
Manipulation of processing and memory for prose through expectation and uncertainty
}

\author{
CHARLES H. CLARK \\ Department of Reading, Western Illinois University, Macomb, Illinois 61455
}

and

\author{
FRANK H. FARLEY \\ Department of Educational Psychology, University of Wisconsin, Madison, Wisconsin 53706
}

\begin{abstract}
This experiment investigated the assumption that children's learning and retention of prose material can be differentially affected by varying discrepancy from expectation (as established by an advance organizer). It was hypothesized that intermediate levels of discrepancy should produce better learning and retention than either the control or the completely discrepant extremes. Completely disorganized passages should seriously debilitate comprehension and retention. From the data obtained, it was found that there was no significant effect on comprehension and retention due to passage condition. The retention interval effect was significant, indicating that forgetting took place. There was also a significant interaction between comprehension type (literal vs. inferential) and retention, suggesting that the learning characterized by one type of question was retained to a greater extent than the other or that probably the original learning of material relevant to one question type was greater than that for the other type. The results were discussed in relation to recall vs. recognition paradigms and recent developments in schema theory.
\end{abstract}

One variable that has been investigated in relation to prose learning and retention is that of arousal (Farley \& Eischens, Note 1). A considerable amount of evidence indicates that physiological arousal is an important contributor to verbal learning and memory (Farley, Note 2). It is generally shown that in list-learning paradigms arousal is differentially related to short- vs. longterm retention, such that high arousal during learning leads to poor short-term but superior long-term retention when compared with the effects of low arousal during learning. Arousal therefore seems to be differentially involved in the processes of short- vs. long-term memory. Where prose learning is concerned, the results have been more complex. Based on the hypothesis that adjunct questions in text would have arousal-attention effects, Farley and Eischens (Note 1) studied such adjunct questions in relation to short- vs. long-term retention in elementary school children. The results indicated that questions generally facilitated both short- and long-term retention. Later research using single inserted high- and low-arousal words indicated facilitation of long-term retention of literal or inferential comprehension with slight or no effects on short-term retention (Farley \& Schmuller, Note 3). The use of long-term retention measures is strongly indicated by this work.

This paper was presented at the 83rd Annual Meeting of the American Psychological Association, Chicago, September 3, 1975. The research was done while the first author was at the University of Wisconsin, Madison. The research and preparation of this report were supported directly or indirectly by the U.S. Department of Health, Education, and Welfare, Center Contract NE-C-00-3-0065, and by the Spencer Foundation.
Another approach to the study of arousal effects in prose has been through the manipulation of expectation and uncertainty. "If a reader is led to expect certain things to occur in the text, certain information to be presented, a certain organization and sequencing of text to take place, then it might be hypothesized that deviations from confirmation of this expectation would be arousing, and would therefore be expected to facilitate long-term retention.... On an hypothesis of an inverted-U shaped relationship between arousal and discrepancy, it would be expected that an intermediate degree of discrepancy, as compared to no discrepancy or a very slight discrepancy and a very marked discrepancy, would be most arousing and thus would most significantly facilitate long-term retention" (Farley, Note 4).

Evidence for such an inverted-U hypothesis in other contexts has been provided by Berlyne (1960). To study expectation and uncertainty effects in prose, Farley (Note 4) employed an advance organizer, followed, depending on the experimental condition, by a narrative passage varying the degree to which it seemed to follow from or agree with the advance organizer. The latter manipulation was produced by varying the degree of randomness of organization of the passage. Thus the passage could be either completely random (all sentences random with regard to each other) or not at all random, with varying degrees in between. It was expected that intermediate discrepancies from expectation (as established by the advance organizer) would be optimally arousing and lead to more active processing of the prose and thus better retention than the other condi- 
tions. One problem in this study was the lack of any specifically logical structure to the passage, which was a descriptive narrative of the activities and features of a mythical primitive tribe. Thus it is possible that no, or relatively small, effects of different methods of passage organization would be found. That is, many different (passage) structural organizations might equally well present the description of tribal activities.

The present study was undertaken as an extension of the foregoing organizational experiment. An attempt was made to bring the formal structural properties of the passage under better control. Most work in prose learning has involved learning from printed text or pictorial material, although much of children's learning is from aural discourse; therefore, auditory presentation of the material was used in this experiment. Such presentation would be expected to enhance any uncertainty or discrepancy effects, since the child is not able to visually compare previous with present information so as to reduce the uncertainty. Thus, the only comparator available to the subject is memory, which is the hypothesized target of the arousal manipulation.

\section{METHOD}

\section{Subjects}

Two hundred and sixty-nine fifth- and sixth-grade students served as subjects. They were obtained from four middle-class Roman Catholic elementary schools, three of which were in a midwestern town of 170,000 population; the fourth was in a small town immediately adjoining that city. All subjects were white. Sex distribution was approximately equal, with 139 girls and 130 boys. The mean age was 11.17 years $(S D=.72)$.

\section{Materials}

The passage to be learned was concerned with the elements of a basic sentence, as described by Thomas (1965). It was 464 words long, with 48 sentences. Readability of the passage was mid to upper third-grade level using the Fry Readability Scale (Fry, 1968) and fifth- to sixth-grade level using the DaleChall Formula (Dale \& Chall, 1948). All teachers indicated that students were currently reading at or near grade level.

Along with the control passage, three further versions were generated by randomizing one-third, two-thirds, or all of the sentences. The procedure consisted of randomly selecting the number of sentences for each version of the passage (e.g., 16 for the one-third version) and randomly reassigning each of these sentences to one of the passage locations the withdrawn sentences originally occupied. In the completely randomized condition, the locations of all 48 sentences were randomly interchanged.

An advance organizer, written to give a general outline of the passage without providing specific information, was constructed in a manner similar to those discussed by Ausubel (1968). The advance organizer was 92 words long and consisted of nine sentences. All subjects received the same advance organizer.

The organizer and passages were recorded by a female professional television and radio announcer. The playing time was $46.25 \mathrm{sec}$ for the advance organizer and $244.50 \mathrm{sec}$ for each of the passages.

The retention test was a 12 -item measure of literal and inferential comprehension of the passage. Each item was a fouroption multiple-choice type, with six of the items reflecting literal and six inferential comprehension. Construction of the items followed procedures recommended by Bormuth (1970). A retention test booklet was employed consisting of 13 pages with one item per page and a demographic information cover sheet.

For those subjects who were not given the short-term retention test, but only the long-term test 1 week later, a "filler" booklet was used that took as long to complete as did the retention test itself and required subjects to fill a page with Xs and Os. This booklet was identical in appearance and number of pages to the test booklet and included the same cover page.

\section{Procedure}

A 4 by 2 by 2 design was employed, consisting of the control passage plus the three variations, two retention intervals, and two types of comprehension items (fact vs. inference). The last factor was a repeated measure in that all subjects received both the fact and inference items. The retention intervals were immediate and 7 days. Passage presentation and retention tests were done in small groups. Immediately upon completion of the passage, short- and long-term booklets were distributed randomly in equal numbers to the subjects in a given group.

The two testing sessions, short- and long-term, were separated by exactly 7 days, with the long-term test being given at the same time of day and in the same room as the short-term test. All subjects in the experiment were given the long-term test, including those who were given the short-term measure previously, although the latter tests were not used for analysis.

At the beginning of the first testing session, a typed copy of the advance organizer was face down on each subject's desk. The experimenter instructed them to turn the copy over and read along with the tape recording. The subjects were not told that a comprehension test would be administered. At the end of the organizer, subjects were told to turn the papers face down again, and these were collected by the experimenter. The temporal interval between the end of the advance organizer and the beginning of the passage was $60 \mathrm{sec}$. No printed copy of the passage itself was given to the subjects. Immediately following presentation of the passage, the test and filler booklets were distributed. Booklets were not collected and no group instructions were given until a standardized $10 \mathrm{~min}$ had elapsed. All timing was covert and standardized.

For the long-term test session 7 days later, the test booklets were distributed to all subjects, and the same standardized instructions as those in the first session were used. The same experimenter was used for both the short-and long-term sessions. The order of test items for each subject was random within passage conditions, but the orders for a given passage condition were duplicated in the remaining passage conditions.

The subjects were not told prior to distribution of the test booklets that they were to be tested, and they were not informed in advance of the 7-day retention test. Following the shortterm session, they were asked not to talk about the passage or the test to others.

\section{RESULTS}

The mean literal and inferential comprehension scores and standard deviations for the various conditions of the experiment are given in Table 1.

The data summarized in Table 1 were subjected to univariate analyses of variance. Results of these analyses indicated no significant effect of passage organization on either literal or inferential recognition comprehension at either retention interval. There were, however, significant effects found between retention interval and comprehension type. The retention interval effect was significant $[F(1,252)=10.716, p<.005]$. The general 
Table 1

Mean Comprehension Scores and Standard Deviations for the Various Groups at Two Retention Intervals

\begin{tabular}{|c|c|c|c|c|c|c|c|c|c|c|}
\hline \multirow[b]{3}{*}{ Passage Condition } & \multicolumn{5}{|c|}{ Short-Term Retention Interval } & \multicolumn{5}{|c|}{ Long-Term Retention Interval } \\
\hline & \multirow[b]{2}{*}{$\mathbf{N}$} & \multicolumn{2}{|c|}{$\begin{array}{c}\text { Literal } \\
\text { Comprehension } \\
\end{array}$} & \multicolumn{2}{|c|}{$\begin{array}{c}\text { Inferential } \\
\text { Comprehension } \\
\end{array}$} & \multirow[b]{2}{*}{$\mathrm{N}$} & \multicolumn{2}{|c|}{$\begin{array}{c}\text { Literal } \\
\text { Comprehension } \\
\end{array}$} & \multicolumn{2}{|c|}{$\begin{array}{c}\text { Inferential } \\
\text { Comprehension }\end{array}$} \\
\hline & & Mean & SD & Mean & SD & & Mean & SD & Mean & SD \\
\hline Control Passage & 32 & 4.063 & 1.625 & 4.938 & 1.243 & 32 & 3.125 & 1.070 & 4.250 & 1.320 \\
\hline One-Third Randomization & 32 & 4.094 & 1.353 & 4.594 & 1.214 & 35 & 2.943 & 1.083 & 4.229 & 1.497 \\
\hline Two-Thirds Randomization & 33 & 3.636 & 1.141 & 4.242 & 1.582 & 35 & 3.286 & 1.073 & 4.600 & 1.479 \\
\hline Complete Randomization & 33 & 3.636 & .994 & 4.758 & 1.226 & 36 & 3.250 & 1.180 & 4.639 & 1.417 \\
\hline
\end{tabular}

comparison of factual to inferential yielded a univariate $\mathrm{F}(1,252)=155.521, \mathrm{p}<.0001$; as can be seen from Table 1, inferential item recognition was higher. The interaction of Retention Interval by Factual Recognition was significant $[F(1,252)=22.291, p<.0001]$, indicating that there was significant forgetting of factual information over time. In contrast, analysis of retention interval by inferential comprehension produced no significant relationship. Thus, factual information was forgotten over time, but inferential was not. The percentage of recognition was as follows: literal short-term, $64.3 \%$; long-term, 52.5\%; inferential short-term, $77.2 \%$; longterm, $73.8 \%$. The mean percent memory loss for the factual questions, collapsed across passage conditions, was $11.8 \%$, while that for inferential questions was $3.4 \%$.

\section{DISCUSSION}

It is clear from the present results that no effect of passage randomization was obtained on either short- or long-term retention or literal vs. inferential comprehension. This study employed a more logically organized passage than that previously used by Farley (Note 4) and increased the memory load requirements over his study, with the results in essential agreement with his findings of no effects either of passage organization or of presence or absence of the advance organizer. The results of the two studies taken together suggest that uncertainty-manipulated arousal may not be effective in influencing comprehension, at least using the general paradigm of these experiments.

It is rather intuitively surprising that the random vs. organized passage structure had no significant effect on recognition comprehension, even though the results replicate those of Farley (Note 4). Two possible explanations for these results may be considered if one assumes no confounding effect attributable to the particular passage or questions utilized. The first of these possibilities is that recognition questions in general are not sensitive to passage organization variables. Dooling and Lachman (1971) and Sulin and Dooling (1974) have indeed argued rather convincingly that this is the case. It is possible to explain this insensitivity using a schema model as a theoretical base (see Bartlett, 1932; Norman \& Bobrow, 1976; Norman \& Rumelhart, 1975; Rumelhart \& Ortony, 1977). Disorganized prose might be expected to activate a more varied pattern of schemata than organized prose. Thus, the recall may be seriously affected by disorganized prose, whereas recognition questions, because they provide cues that could access the various relevant schemata, may enable subjects to successfully recall the correct answer. This, of course, assumes that most of the information from a randomized passage is successfully stored in some form or another.

The second possible explanation for the apparent insensitivity of recognition questions to passage organization is simply that subjects successfully reorganized such prose into a reasonable facsimile of the original version during comprehension. The resulting organized memorial representative would, then, facilitate both correct recognition responses and organized recall. This explanation is supported by a study conducted by Mandler and Johnson (1977), who found that even young school children produced well-organized recall protocols after exposure to poorly organized stories. Kintsch and Vipond (1978) have recently developed a processing model which, in fact, provides an explanation of the processing typically involved in this type of reorganizational comprehension. Briefly,' a comprehender will attempt to maintain in working memory a set of idea units, or propositions, until it can be connected into a meaningful chunk. If there is a lack of interconnections between the propositions (as would often be the case in a randomized prose sample), a search for a connecting link (reinstatement search) is instituted. A reinstatement search can be successful, in which case the necessary link is found and utilized, or unsuccessful. An unsuccessful reinstatement search may be resolved through the construction of an inference that forms an appropriate connection, or the memory system may attempt to store the information in its unconnected state. Data collected by Clark (Note 5) support these hypotheses for free recall of connected discourse, supplying evidence that intersentential-evel text disruption negatively affects the amount, but not necessarily the organization, of what is recalled. Either of these possibilities could explain the successful performance of subjects on the recognition questions in the present study. Hopefully, further research will be conducted that will result in a more thorough understanding of precisely what types of processing are involved in the comprehension of prose, particularly as it relates to organizational factors.

The lack of significant memory loss for inferential comprehension over 7 days, compared with the significant loss for literal comprehension, is of great interest and is in line with Farley's (Note 4) earlier data. This interaction of Comprehension Type by Retention Interval should be further investigated in studies aimed specifically at identifying differences between literal and inferential processing of prose.

\section{REFERENCE NOTES}

1. Farley, F. H., \& Eischens, R. R. Children's processing of prose: The effects of question arousal, text complexity, and learner strata on short- and long-term retention (Tech. Rep. 201). Madison, Wis: Wisconsin Research and Development Center for Cognitive Learning, 1971.

2. Farley, F. H. Learning from discourse: Short-and long-term retention in the paired-associate and connected discourse learning of children and adults as a function of intrinsic arousal (Working Paper 103). Madison, Wis: Wisconsin Research and Development Center for Cognitive Learning, 1972.

3. Farley, F. H., \& Schmuller, J. Children's learning from discourse: Word arousal and spread-of-arousal effects in short-and long-term retention (Tech. Rep. 242). Madison, Wis: Wisconsin Research and Development Center for Cognitive Learning, 1972. 
4. Farley, F. H. Children's learning from discourse: Advance organizer, text sequence, and arousal effects of literal and inferential comprehension (Tech. Rep. 265). Madison, Wis: Wisconsin Research and Development Center for Cognitive Learning, 1972.

5. Clark, C. H. Prose organization and its effect on recall organization. Manuscript submitted for publication, 1980.

\section{REFERENCES}

Ausubel, D. Educational psychology. New York: Holt, Rinehart, \& Winston, 1968.

BARTLETT, F. C. Remembering: $A$ study in experimental and social psychology. Cambridge: Cambridge University Press, 1932.

Berlyne, D. E. Conflict, arousal, and curiosity. New York: McGraw-Hill, 1960.

Bormuth, J. R. On the theory of achievement test items. Chicago: University of Chicago Press, 1970.

Dale, E., \& Chall, J. A formula for predicting readability. Educational Research Bulletin, 1948, 27, 11-20.

Dooling, D. J., \& Lachman, R. Effects of comprehension on retention of prose. Journal of Experimental Psychology, 1971, 88, 216-222.

FRY, E. B. A readability formula that saves time. Journal of Reading, 1968, 11, 513-516.
KINTSCH, W., \& ViPOND, D. Reading comprehension and readability in educational practice and psychological theory. In L. G. Nilsson (Ed.), Memory: Processes and problems. Hillsdale, N.J: Erlbaum, 1978.

Mandle R, J. M., \& Johnson, N. S. Remembrance of things parsed: Story structure and recall. Cognitive Psychology, 1977, 9, 111-151.

Norman, D. A., \& Bobrow, D. G. On the role of active memory processes in perception and cognition. In C. N. Cofer (Ed.), The structure of human memory. San Francisco: Freeman, 1976.

Norman, D. A., \& Rumelhart, D. E. Explorations in cognition. San Francisco: Freeman, 1975.

Rumelhart, D. E., \& Ortony, A. The representation of knowledge in memory. In R. C. Anderson, R. J. Spiro, \& W. E. Montague (Eds.), Schooling and the acquisition of knowledge. Hillsdale, N.J: Erlbaum, 1977.

Sulin, R. A., \& Dooling, D. J. Intrusion of a thematic idea in retention of prose. Journal of Experimental Psychology, $1974,103,255-262$.

Tномаs, O. Transformational grammar and the teaching of English. New York: Holt, Rinehart, \& Winston, 1965.

(Received for publication July 28, 1980.) 